Stefan George und sein Kreis

2. Auflage

Band 1 



\section{Stefan George und sein Kreis}

Ein Handbuch

2. Auflage

\section{Band 1}

Herausgegeben von

Achim Aurnhammer, Wolfgang Braungart, Stefan Breuer und Ute Oelmann

in Zusammenarbeit mit

Kai Kauffmann

Redaktion: Birgit Wägenbaur

De Gruyter 
Das Handbuch wurde vom 1.6.2007 bis 30.11.2011 unter dem Geschäftszeichen BR 995/2 von der Deutschen Forschungsgemeinschaft gefördert.

Redaktionelle Mitarbeit: Markus Pahmeier

ISBN 978-3-11-044101-7

e-ISBN (PDF) 978-3-11-045688-2

e-ISBN (EPUB) 978-3-11-045670-7

Library of Congress Cataloging-in-Publication Data

A CIP catalog record for this book has been applied for at the Library of Congress.

Bibliografische Information der Deutschen Nationalbibliothek

Die Deutsche Nationalbibliothek verzeichnet diese Publikation in der Deutschen Nationalbibliografie; detaillierte bibliografische Daten sind im Internet über http://dnb.dnb.de abrufbar.

(C) 2016 Walter de Gruyter GmbH, Berlin/Boston

Einbandabbildung: ,Dichtertafel', Beilage zur siebten Folge der Blätter für die Kunst (1904);

Aufnahme: Stefan George Archiv

Satz: pagina GmbH, Tübingen

Druck: Hubert \& Co. GmbH \& Co. KG, Göttingen

@ Gedruckt auf säurefreiem Papier

Printed in Germany

www.degruyter.com 